DOI: https://doi.org/10.47405/mjssh.v6i5.784

\begin{tabular}{|c|c|}
\hline$x+\frac{1}{20}$ & Malaysian Journal of Social Sciences and Humanities (MJSSH) \\
\hline $\begin{array}{l}\text { Malaysian Journal of } \\
\text { Socai sciences and }\end{array}$ & Volume 6, Issue 5, May 2021 \\
\hline (MJ-sSH) & e-ISSN : 2504-8562 \\
\hline & $\begin{array}{l}\text { Journal home page: } \\
\text { www.msocialsciences.com }\end{array}$ \\
\hline
\end{tabular}

\title{
Kesediaan Untuk Berubah Guru dan Amalan Pembelajaran Abad Ke-21: Guru Sebagai Mediator Terhadap Pelaksanaan Kemahiran Berfikir Aras Tinggi Guru di Sekolah Menengah Negeri Sabah
}

\author{
Fadzilah binti Patman1, Mohd Khairuddin @ Jerry bin Abdullah² \\ ${ }^{1}$ SK. Rugading Tuaran, Sabah, Malaysia \\ ${ }^{2}$ Fakulti Psikologi dan Pendidikan, Universiti Malaysia Sabah (UMS) \\ Correspondence: Fadzilah binti Patman (fadz_dila@yahoo.com.my)
}

\begin{abstract}
Abstrak
Penyelidikan ini dijalankan adalah bertujuan untuk mengkaji persepsi guru mengenai kesediaan untuk berubah guru, amalan pembelajaran abad ke-21guru dan pelaksanaan kemahiran berfikir aras tinggi atau KBAT dalam kalangan guru sekolah menengah di negeri Sabah. Kajian kuantitatif dan bukan eksperimental ini juga menggunakan kaedah tinjauan. Selain itu, kajian ini turut menggabungkan beberapa teknik pensampelan iaitu rawak kluster, rawak berstrata dan rawak mudah. Data diperoleh dengan mengedarkan satu set borang soal selidik yang telah adaptasi daripada penyelidik asal. Seramai 400 orang responden yang terdiri daripada guru sekolah menengah di negeri Sabah telah menjawab soal selidik tersebut. Data dianalisis melalui kaedah statistik deskriptif dan inferensi yang menggunakan perisian IBM SPSS dan AMOS-SEM Statistics. Dapatan kajian menunjukkan kesediaan untuk berubah guru, amalan pembelajaran abad ke-21 guru dan pelaksanaan KBAT guru diamalkan pada tahap yang tinggi. Kajian juga membuktikan bahawa terdapat hubungan dan pengaruh secara langsung dan tidak langsung yang signifikan antara kesediaan untuk berubah guru dan pembelajaran abad ke-21 terhadap pelaksanaan KBAT guru. Akhir sekali, implikasi serta cadangan kajian lanjut juga turut dibincangkan dalam penyelidikan ini.
\end{abstract}

Kata kunci: kesediaan untuk berubah guru, pembelajaran abad ke-21, pelaksanaan KBAT guru, kemahiran berfikir aras tinggi, sekolah menegah

\section{Readiness to Change Teachers and $21^{\text {st }}$ Century Learning Practices: Teachers as Mediator on the Implementation of Teachers' Higher Order Thinking Skills in Sabah State Secondary School}

\begin{abstract}
This research is conducted to examine teachers' perceptions on the readiness to change teachers, $21^{\text {st }}$ century learning practices teachers and the implementation of teachers' higher order thinking skills or HOTS among secondary school teachers in Sabah. This quantitative and non-experimental study also used survey methods. Meanwhile, this study also combines several sampling techniques namely cluster random, stratified random and sampel random. Data were obtained by distributing a set of questionnaires that had been adapted from the original researchers. A total of 400 respondents consisting of secondary school teachers in Sabah answered the questionnaire. Data were analyzed through descriptive and inferential statistics method using IBM SPSS and AMOS SEM Statistics software. The findings of the study show that the readiness to change teachers, the $21^{\text {st }}$ century learning
\end{abstract}


practices teachers and the implementation of teachers' HOTS are practiced at a high level. The study also proves that there is a significant direct and indirect relationship and influence between the readiness to change teachers and $21^{\text {st }}$ century learning practices teachers on the implementation of teachers' HOTS. Finally, the implications and suggestions of further research are also discussed in this research.

Keywords: readiness to change teachers, $21^{\text {st }}$ century learning practices teachers, implementation of teachers' HOTS, higher order thinking skills, secondary school

\section{Pengenalan}

Transformasi dalam sistem pendidikan di Malaysia pada masa kini telah memberi tumpuan terhadap konsep berfikir aras tinggi atau lebih dikenali dengan singkatan akronim KBAT. Konsep KBAT ini dijangka berupaya melahirkan generasi modal insan yang mampu bersaing di peringkat global. Selari dengan pandangan yang diutarakan dalam kajian Raiyan dan Tilchin (2015) yang menyatakan bahawa KBAT adalah cabaran multidimensi pendidikan yang rumit pada era ini. Selain itu, Chen (2016) juga turut menjelaskan konsep KBAT telah menjadi komponen penting dalam kurikulum pendidikan dan matlamat yang telah ditetapkan. Maka dengan itu, peranan guru sangat signifikan dalam melengkapkan pelajar dengan kebolehan kognitif pada tahap yang tinggi bagi mendorong mereka berfikir secara lebih kritis dan proaktif. Rentetan itu, senario ini telah membawa kepada satu perubahan dan pembaharuan dalam sistem pendidikan bagi banyak negara di seluruh dunia termasuklah Malaysia.

Justeru itu, berikutan trend sistem pendidikan semasa yang sentiasa berubah-ubah, maka situasi ini telah menuntut kesediaan untuk berubah guru bagi mengendalikan perubahan tersebut sesuai dengan keperluan semasa (Ismail, Hamzah \& Lubis, 2016). Kesediaan untuk berubah guru dalam konteks kajian ini adalah berfokuskan kepada pelaksanaan KBAT yang lebih berkesan. Hal ini adalah kerana guru merupakan agen perubahan pendidikan yang berperanan penting dalam melaksanakan hasrat negara bagi memastikan kemenjadian dan keberhasilan murid terlaksana dengan sebaiknya (Salina \& Zamri, 2017). Nik Noraini dan Noor Hisham (2018) berpendapat bahawa peranan guru sudah jauh berubah dan akan terus berubah menjadi lebih mencabar pada masa akan datang.

Oleh yang demikian, guru bukan sahaja perlu memiliki pengetahuan, kemahiran serta sikap, tetapi juga membolehkan para guru menjadi agen perubahan yang sensitif sesuai dengan keperluan masyarakat. Sekali gus, diharap kesediaan untuk berubah guru ke arah pelaksanaan KBAT yang berkesan dapat memacu kualiti sistem pendidikan negara ke tahap yang lebih tinggi setanding dengan negara-negara maju di dunia.

\section{Pernyataan Masalah}

Pelaksanaan KBAT di Sabah menjadi fokus utama dalam penyelidikan ini bersesuaian dengan matlamat Jabatan Pendidikan Negeri Sabah yang meletakkan KBAT sebagai salah satu daripada 24 KPI yang ingin dicapai dengan sekurang-kurangnya mendapat satu taraf cemerlang dalam penarafan KBAT berdasarkan SKPMg2 pada tahun 2019. Walau bagaimanapun, hanya 7 buah sekolah sahaja yang berjaya mencapai taraf cemerlang tersebut daripada 48 buah sekolah yang mewakili 24 buah Pejabat Pendidikan Daerah masing-masing (Jabatan Pendidikan Negeri Sabah, 2018). Terdapat beberapa penyelidik iaitu Nor Hasmaliza et al. (2016) dan Wan et al. (2017) yang mendapati bahawa guru kurang diberi pendedahan berkaitan strategi dan kaedah pengajaran serta pedagogi KBAT menjadi punca pelaksanaan KBAT kurang memberangsangkan.

Seterusnya, aspek kesediaan untuk berubah guru juga turut menjadi salah satu fokus yang dikaji dalam penyelidikan ini kerana kesediaan untuk berubah guru merupakan salah satu pakej yang perlu sentiasa ada pada seorang guru bagi memastikan pelaksanaan KBAT dapat dijayakan. Guru adalah agen pelaksana kurikulum, agen perubahan serta menjadi tonggak kejayaan terhadap sistem pendidikan 
negara (Nik Noraini et al., 2018). Hal yang demikian adalah kerana pelaksanaan KBAT merupakan salah satu aspek yang masih dianggap baharu dalam sistem pendidikan. Oleh itu, usaha ini sangat memerlukan kesediaan untuk berubah guru bagi melaksanakannya (Salina \& Zamri, 2017).

Tambahan pula, faktor kesediaan untuk berubah guru yang tinggi diyakini dapat mempengaruhi kesiapsiagaan guru untuk menerima dan menambah ilmu pengetahuan tentang pelaksanaan KBAT. Seterusnya, dapat meningkatkan kemahiran guru dan merangsang sikap guru menjadi lebih positif terhadap pelaksanaan KBAT. Namun, kesediaan untuk berubah guru adalah agak minima atau kurang dalam melaksanakan sesuatu perubahan seperti yang dilaporkan dalam kajian Wan Nor Shairah \& Norazah (2017). Oleh itu, kajian ini diharap dapat merungkai persoalan yang timbul berkaitan faktor kesediaan untuk berubah guru dan pengaruh serta hubungannya terhadap pelaksanaan KBAT di Sabah.

Selain itu, amalan Pembelajaran Abad ke-21 guru merupakan pemboleh ubah pengantara atau mediator dalam kajian ini yang berperanan sebagai pemboleh ubah tidak bersandar dan juga pemboleh ubah bersandar kedua. Pembelajaran Abad ke-21 sememangnya sangat berkait rapat dengan pelaksanaan KBAT kerana terkandung elemen berfikir secara kritis. Oleh itu, permasalahan berhubung amalan pembelajaran abad ke-21 guru turut memberi kesan terhadap pelaksanaan KBAT. Antara permasalahan berkaitan pembelajaran abad ke-21 guru adalah kemahiran pedagogi berunsurkan KBAT masih rendah. Hal ini berlaku adalah disebabkan kompetensi guru dan dinamika guru terhadap perubahan pendidikan adalah pada tahap yang rendah. Terdapat beberapa penyelidikan yang konsisten dengan dapatan tersebut iaitu Nurzarina dan Rosalinda (2015), Badrul et al. (2016), Rohani et al. (2017), Mohd Nazmi et al. (2018) dan Mistrine et al. (2018).

\section{Objektif Kajian}

Objektif kajian ini adalah untuk mengenal pasti sama ada terdapat hubungan dan pengaruh secara langsung dan tidak langsung bagi kesediaan untuk berubah guru terhadap pelaksanaan KBAT dalam kalangan guru di sekolah menengah negeri Sabah.

\section{Metod Kajian}

Dalam penyelidikan ini pendekatan yang digunakan ialah kuantitatif. Hal ini adalah kerana hubungan antara kesediaan untuk berubah guru dengan pelaksanaan KBAT serta Pembelajaran Abad ke-21 sebagai pemboleh ubah pengantara atau mediator merupakan suatu kajian yang berbentuk Sains Sosial. Menurut, Chua (2006) dan Creswell (2009) kaedah tinjauan adalah kaedah yang sangat popular digunakan dalam kajian bagi bidang Sains Sosial. Oleh itu, reka bentuk kajian adalah bukan eksperimen. Di samping itu, responden pula dipilih berdasarkan kaedah rawak mudah. Selain itu, analisis statistik SEM AMOS pula digunakan untuk mengkaji hubungan dan pengaruh secara langsung dan tidak langsung antara kesediaan untuk berubah guru dengan Pelaksanaan KBAT dan Pembelajaran abad ke-21 berperanan sebagai pemboleh ubah pengantara atau mediator.

Sehubungan itu, dari sudut instrumen kajian pula penyelidik menggunakan kaedah borang soal selidik untuk memperolehi maklumat yang sahih, tepat dan betul. Instrumen kajian yang digunakan juga adalah diadaptasi daripada beberapa sumber berdasarkan kepada kesesuaian kajian. Antaranya ialah Readiness for Change Questionnaire II (RFCQ-II) oleh Holt (2002) dan Readiness for Organizational Change Measure (ROCM) oleh Holt et al. (2007), $21^{\text {st }}$ Century Teaching and Learning Survey oleh Hixson et al. (2012) dan Soal selidik Teaching of Higher Order Thinking Skills oleh Rajendran (1998). Kesahan dan kebolehpercayaan instrumen kajian telah dijalankan. Didapati bahawa nilai alpha Cronbach (kebolehpercayaan) dan Kaiser Mayer Olkin (analisis faktor) bagi instrumen tersebut secara keseluruhan bagi kedua-dua nilai adalah melebihi 0.80. Alat ukur kajian ini telah melalui proses adaptasi dan telah disesuaikan dengan konteks kajian ini. Di samping itu, alat ukur ini juga telah diuji dan disahkan oleh pakar dalam bidang berkaitan serta telah melalui prosedur yang ketat. Selain itu, responden yang terlibat dalam kajian ini adalah terdiri daripada 400 orang guru daripada 12 buah Pejabat Pendidikan Daerah serta enam bahagian dalam negeri Sabah. 


\section{Dapatan Kajian}

Analisis SEM AMOS dijalankan adalah bagi melihat sama ada terdapat hubungan dan pengaruh secara langsung dan tidak langsung kesediaan untuk berubah guru terhadap pelaksanaan KBAT dalam kalangan guru di sekolah menengah negeri Sabah dengan amalan pembelajaran abad ke-21 guru sebagai pemboleh ubah pengantara atau mediator. Analisis ini adalah bertujuan untuk menentukan peranan pemboleh ubah pengantara atau mediator sama ada wujud atau tidak serta jenis mediator yang terhasil daripada analisis ini.

Seterusnya, dalam ujian ini juga cadangan Baron dan Kenny (1986) dirujuk bagi menentukan pemboleh ubah pengantara atau mediator. Berpandukan saranan Baron dan Kenny (1986), ujian pengantaraan (mediation) boleh dijalankan dengan melakukan anggaran koefisien yang berasingan menggunakan tiga persamaan regresi. Manakala, jenis pengantaraan atau mediator ditentukan melalui pengujian hipotesis ke atas kesan langsung c. Pengantaraan sempurna wujud apabila pemboleh ubah bebas tidak memberi kesan kepada pemboleh ubah terikat iaitu laluan $\mathrm{c}$ adalah tidak signifikan. Sebaliknya, kesan mediator separa (partial mediator) terhasil apabila hubungan dan pengaruh secara langsung pemboleh ubah bebas terhadap pemboleh ubah terikat adalah signifikan iaitu pada laluan $\mathrm{c}$. Rajah 1 di bawah menerangkan saranan Baron dan Kenny (1986) berhubung penentuan peranan variabel pengantara atau mediator dalam kajian.

Sehubungan itu, dapatan kajian diperoleh setelah prosedur bagi menentukan nilai kesepadanan model kajian telah dicapai iaitu melalui prosedur CFA (Confirmatory Faktor Analysis). Setelah kesemua nilai kesepadanan model yang ditetapkan dalam analisis SEM AMOS dapat dicapai dan telah dipenuhi seperti dalam gambar Rajah 2. Maka, baharulah peranan mediator boleh ditentukan melalui hubungan dan pengaruh menggunakan hipotesis laluan $\mathrm{a}, \mathrm{b}$ dan c seperti rajah 1.

Rajah 1: Prosedur untuk menguji pemboleh ubah pengantara atau mediator

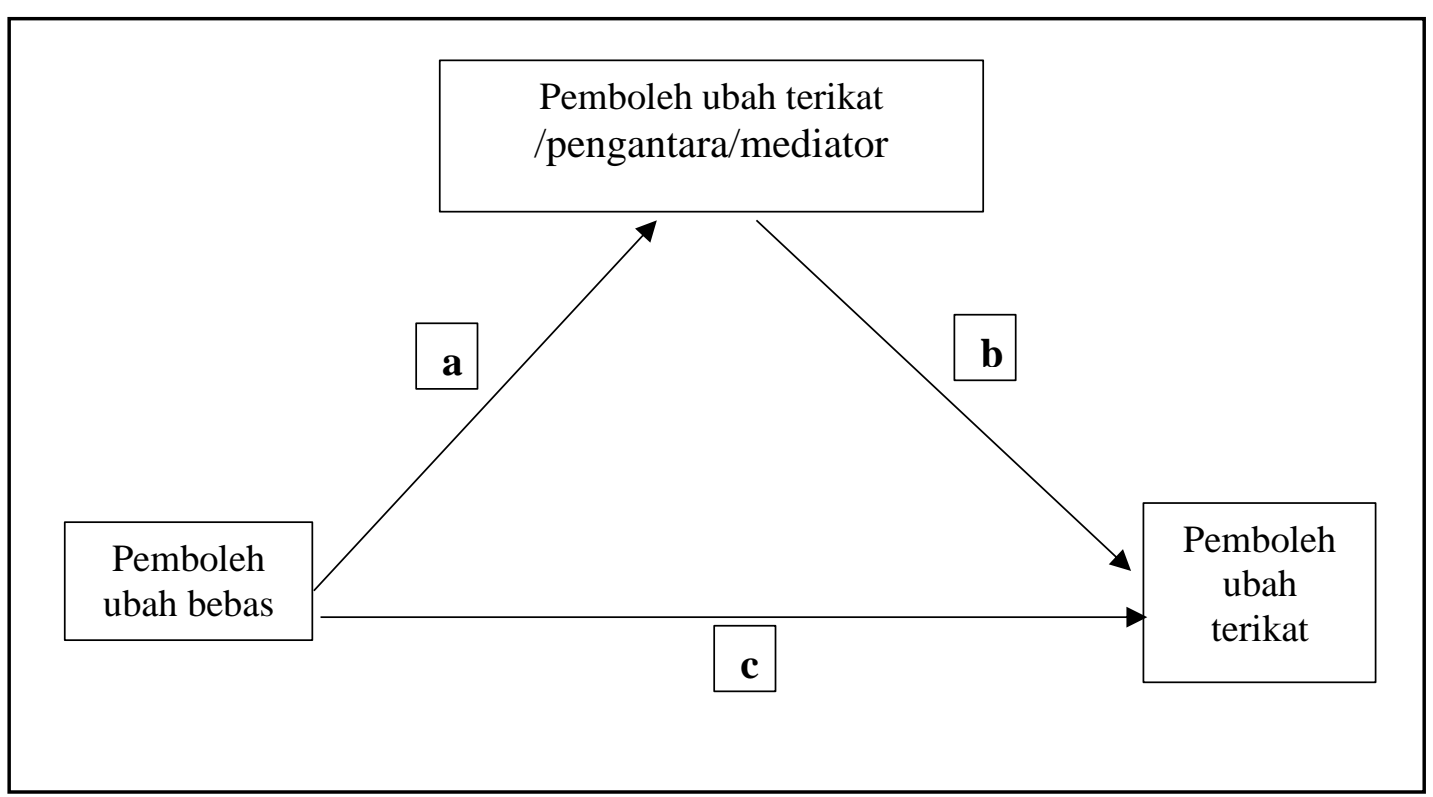

Sumber: Baron \& Kenny (1986)

Hasil analisis SEM AMOS ditunjukkan dalam rajah 2 di bawah. Dapat diperhatikan bahawa nilai pekali regresi piawai (standardized regression weights) dan nilai kebarangkalian ( $p$-value) yang menunjukkan nilai kesignifikinan untuk laluan masing-masing dalam Jadual 1. Lakaran bentuk segitiga yang diperlukan untuk menguji mediator ditunjukkan dalam rajah 3. Manakala, jadual 2 adalah hasil hipotesis bagi setiap laluan hubungan untuk menentukan jenis pengantara atau mediator. 
DOI: https://doi.org/10.47405/mjssh.v6i5.784

Rajah 2: Pekali Regresi Piawai untuk setiap laluan dalam model

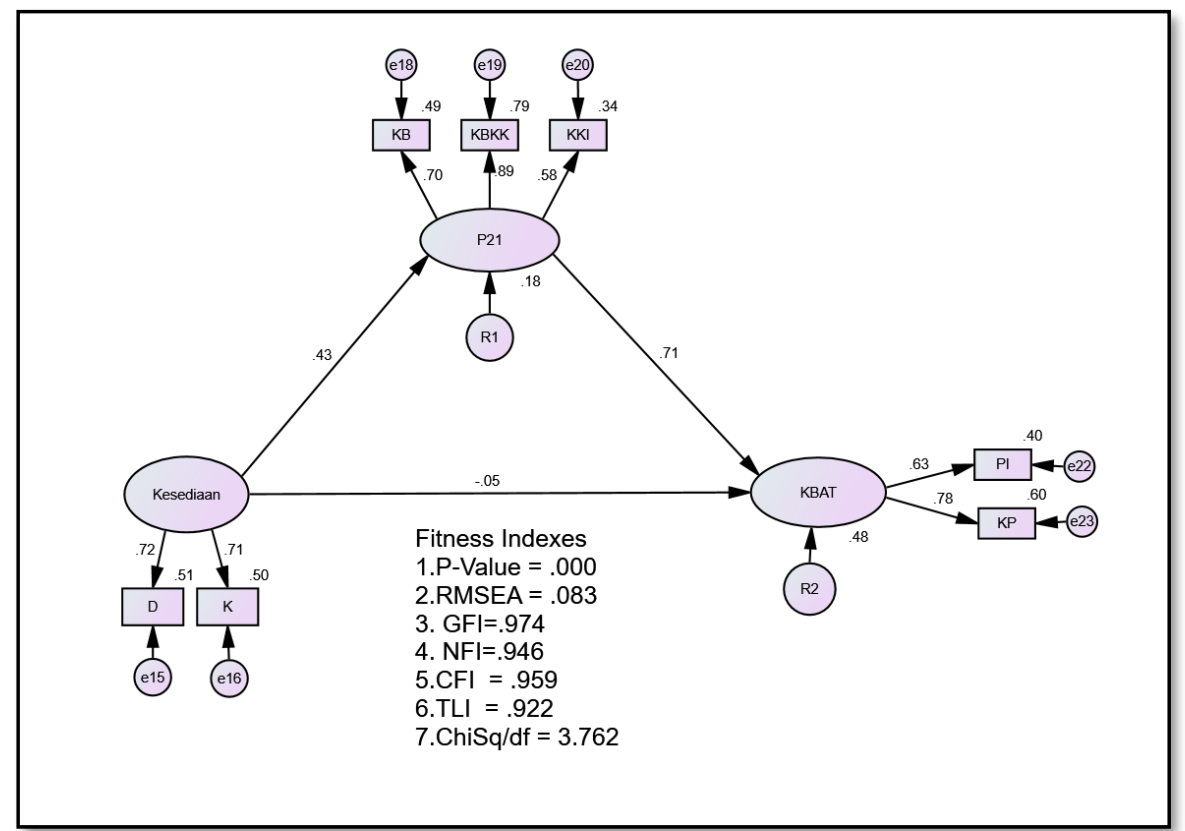

Jadual 1: Pekali regresi piawai dan kesignifikannya bagi setiap laluan

\begin{tabular}{llllll}
\hline Pemboleh ubah & Laluan & Pemboleh ubah & $\begin{array}{l}\text { Regresi } \\
\text { Piawai }\end{array}$ & $\begin{array}{l}\text { Nilai } \\
\mathbf{p}\end{array}$ & Keputusan \\
\hline $\begin{array}{l}\text { Pembelajaran Abad } \\
\text { ke-21 }\end{array}$ & $<----$ & $\begin{array}{l}\text { Kesediaan untuk berubah } \\
\text { guru }\end{array}$ & 0.35 & 0.00 & signifikan \\
Pelaksanaan KBAT & $<----$ & $\begin{array}{l}\text { Pembelajaran Abad ke-21 } \\
\text { Pelaksanaan KBAT }\end{array}$ & 0.72 & 0.00 & $\begin{array}{l}\text { Signifikan } \\
\text { <---- }\end{array}$ \\
\hline & $\begin{array}{l}\text { Kesediaan untuk berubah } \\
\text { guru }\end{array}$ & -0.04 & 0.51 & $\begin{array}{l}\text { Tidak } \\
\text { signifikan }\end{array}$ \\
\hline
\end{tabular}

Signifikan pada aras $\mathrm{p}<0.05$

Rajah 3: Prosedur bagi menguji mediator dalam model

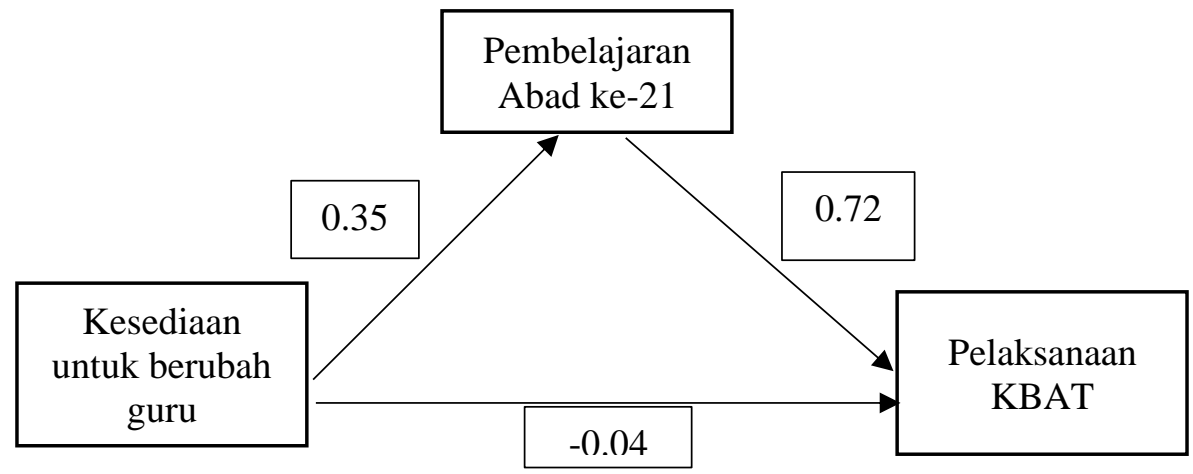

1) Kesan tidak langsung $=0.35 \times 0.72=0.25$

2) Kesan langsung $=-0.04$.

3) Kesan tidak langsung > kesan langsung, kesan mediator wujud.

4) Kedua-dua laluan tidak langsung adalah signifikan.

5) Jenis pengantaraan di sini ialah mediator penuh (full mediation) kerana kesan langsung tidak signifikan. 
Seterusnya, bagi menentukan jenis mediator maka hipotesis bagi setiap laluan ditetapkan seperti di bawah ini.

Hb: Pembelajaran abad ke-21 menjadi mediator dalam hubungan antara kesediaan untuk berubah guru dan Pelaksanaan KBAT

Jadual 2: Tiga sub hipotesis yang terlibat bagi setiap ujian mediator

\begin{tabular}{llll}
\hline $\begin{array}{l}\text { Pernyataan Hipotesis bagi Analisis Laluan (tiga sub } \\
\text { hipotesis) }\end{array}$ & Anggaran & $\begin{array}{l}\text { Nilai } \\
\text { P }\end{array}$ & $\begin{array}{l}\text { Keputusan } \\
\text { Hipotesis }\end{array}$ \\
\hline $\begin{array}{l}\text { Hb1: Kesediaan untuk berubah guru mempunyai kesan } \\
\text { signifikan terhadap Pembelajaran Abad ke-21 }\end{array}$ & 0.68 & 0.00 & Disokong \\
$\begin{array}{l}\text { Hb2: Pembelajaran abad ke-21 mempunyai kesan signifikan } \\
\text { terhadap pelaksanaan KBAT }\end{array}$ & 0.10 & 0.00 & Disokong \\
$\begin{array}{l}\text { Hb3: Kesediaan untuk berubah guru mempunyai kesan } \\
\text { signifikan terhadap pelaksanaan KBAT }\end{array}$ & 0.62 & 0.51 & $\begin{array}{l}\text { Tidak } \\
\text { disokong }\end{array}$ \\
\hline
\end{tabular}

Daripada hasil hipotesis dalam jadual 3 membuktikan bahawa Pembelajaran abad ke-21 menjadi mediator dalam hubungan antara kesediaan untuk berubah guru dan Pelaksanaan KBAT. Jenis mediator yang diperoleh adalah mediator penuh (full mediation) kerana kesan langsung adalah tidak signifikan.

\section{Perbincangan dan Implikasi}

Dapatan dalam kajian ini memberikan implikasi dan manfaat yang sangat berfaedah bagi hubungan dan pengaruh kesediaan untuk berubah guru terhadap pelaksanaan KBAT dengan peranan pembelajaran abad ke-21 guru sebagai pengantara. Sungguhpun penyelidikan ini hanya tertumpu kepada pelaksanaan KBAT di negeri Sabah sahaja, namun penemuan ini boleh diaplikasikan juga oleh guru-guru di seluruh Malaysia secara amnya. Diharap penyelidikan ini dapat menambah baik lagi pelaksanaan KBAT guru di sekolah. Seterusnya, dapat meningkatkan prestasi sekolah serta memperhebatkan lagi kualiti pendidikan terutamanya di negeri Sabah. Justeru itu, perbincangan dalam bahagian ini adalah lebih tertumpu kepada implikasi penyelidikan serta pengalaman. Secara kesimpulannya, kewujudan amalan pembelajaran abad ke-21 guru sebagai mediator dalam hubungan antara kesediaan untuk berubah guru dengan pelaksanaan KBAT menunjukkan perkaitan yang sangat kuat. Hal ini menerangkan bahawa hubungan kesediaan untuk berubah guru terhadap pelaksanaan KBAT guru di sekolah memerlukan amalan pembelajaran abad ke-21 guru sebagai medium. Dengan adanya amalan pembelajaran abad ke21 guru, maka kesediaan untuk berubah guru terhadap pelaksanaan KBAT dapat dipertingkatkan.

Hal ini bertitik tolak daripada aspek pelaksanaan KBAT yang dilihat sebagai elemen penting untuk membangunkan kualiti pendidikan negara supaya setanding dengan pendidikan di peringkat global. Oleh itu, para guru bukan sahaja perlu menguasai ilmu pengetahuan berkaitan pelaksanaan KBAT, tetapi juga memiliki kemahiran pedagogi dalam pelaksanaan KBAT serta mempunyai sikap yang positif terhadap pelaksanaan KBAT. Hasil kajian ini diharap dapat membuka ruang dan memberi peluang kepada pengkaji akan datang untuk membuat penyelidikan berhubung kesediaan untuk berubah guru terhadap pelaksanaan KBAT guru dengan amalan pembelajaran abad ke-21 guru sebagai mediator.

\section{Kesimpulan}

Hasil penemuan kajian ini mendapati bahawa terdapat hubungan dan pengaruh secara tidak langsung kesediaan untuk berubah guru terhadap pelaksanaan KBAT guru dengan amalan pembelajaran abad ke21 sebagai mediator. Kesediaan untuk berubah guru amat diperlukan bagi membolehkan semua guru 
sentiasa bersiap sedia dalam memastikan pelaksanaan KBAT di sekolah dijalankan dengan jayanya. Sementara itu, pembelajaran abad ke-21pula adalah medium yang diperlukan dalam menghasilkan suatu pelaksanaan KBAT guru yang berkesan iaitu melalui beberapa elemen kemahiran yang terdapat dalam pembelajaran abad ke-21 itu sendiri. Dari sudut perspektif perkembangan ilmu, penyelidikan ini menyumbang suatu pengetahuan baharu mengenai kesediaan untuk berubah guru dan pembelajaran abad ke-21 sebagai pengantara atau mediator terhadap pelaksanaan KBAT guru khususnya di negeri Sabah dan Malaysia secara amnya. Pelaksanaan KBAT guru yang berkesan dari aspek penguasaan ilmu, kemahiran pedagogi dan sikap guru terhadap pelaksanaan KBAT diyakini mampu meningkatkan kualiti pendidikan di Malaysia.

\section{Rujukan}

Ainun Rahmah Iberahim, Zamri Mahamod, \& Wan Muna Ruzana Wan Mohamad. (2017). Pembelajaran abad ke-21 dan pengaruhnya terhadap sikap, motivasi dan pencapaian bahasa Melayu pelajar sekolah menengah. Jurnal Pendidikan Bahasa Melayu, 7(2), 77-88.

Badrul Hisham Alang Osman \& Mohd Nasruddin Basar. (2016). Amalan Pengajaran dan Pembelajaran Abad ke-21 dalam Kalangan Pensyarah Institut Pendidikan Guru Kampus Ipoh. Jurnal Pendidikan Dedikasi, 1, 1-25.

Baron, Reuben M. \& David A. Kenny. (1986). Moderator-Mediator Variables Distinction in Social Psychological Research: Conceptual, Strategic and Statistical Consideration. Journal of Personality and Social Psychology, 51(6), 1173-82.

Bloom, B A. (1956). Taxonomy of Education Objectives-Book 1 Cognitive Domain. London: Longman Group Limited.

Chen, M.H. (2016). Theoretical Framework for Integrating Higher-order Thinking into L2 Speaking.Theory and Practice in Language Studies, 6(2), 217.

Chew, B. G. (2017). Pengetahuan dan Pengaplikasian Kemahiran Berfikir Aras Tinggi dalam Kalangan Guru Teknik dan Vokasional. Batu Pahat: Universiti Tun Hussein Onn Malaysia.

Chua, Y. P. (2006). Kaedah dan Statistik Penyelidikan. Kuala Lumpur: McGraw Hill.

Creswell, J. W. (2009). Research Design: Qualitative, Quantitative, and Mixed Method Approaches $\left(3^{r d} e d\right)$. USA: Sage Publication, Inc

Hixon, N., Ravitz J. \& Wishman, A. (2012). Extended Professional Development in Project- Based Learning : Impact on 21st Century Teaching and Studentt Achievement. Charleston, WV: West Virginia Department of Education. Dipetik dari https://www.academia.edu/1999374 pada 20 Julai 2019.

Holt, D. T. (2002). Readiness for Change: The Development of a Scale. Alabama: Auburn University.

Holt, D. T., Armenakis, A. A., Feild, H. S., \& Harris, S. G. (2007). Readiness for Organizational Change: The Systematic Development of a Scale. The Journal of Applied Behavioral Science, 43(2).

Ismail, W. A. W., Hamzah, M. I., \& Lubis, M. A. (2016). Kesediaan Guru Pendidikan Islam Sekolah Rendah di Selangor terhadap Penerapan KBAT dalam Pengajaran dan Pembelajaran. Journal of Advanced Research in Social and Bahavioral Sciences, 3(1), 79-95.

James Ang Jit Eng. (2017). Panduan Pelaksanaan Pendidikan Abad ke-21. Nilai: Institut Aminuddin Baki, Kementerian Pendidikan Malaysia.

Mistrine Radin, \& M. Al Muz zammil Yassin. (2018). Perlaksanaan Pendidikan Abad ke-21 di Malaysia : Satu Tinjauan Awal. Sains Humanika, 10(3-2), 1-6.

Mitana, J. M. V., Muwagga, A. M., \& Ssempala, C. (2018). Assessment of Higher Order Thinking Skills: A Case of Uganda Primary Leaving Examinations. African Educational Research Journal, 6(4), 240-249.

Mohd Nazmi Jaafar, \& Bushro Ali. (2018). Pendekatan Gamifikasi dalam Pengajaran dan Pemudahcaraan Bahasa Arab PAK21. Proceedings of International Conference on The Future of Education IConFEd) 2018, Institute of Teacher Education Tuanku Bainun Campus, Penang, Malaysia, 101-126.

Nik Noraini Raja Abdullah, \& Noor Hisham Md Nawi. (2018). Kesediaan untuk Berubah dalam Kalangan Guru Sekolah Rendah di Negeri Kelantan (Readiness for Change Among Primary 
School Teachers in Kelantan). Online Journal of Language, Communication, and Humanities, 1 , $40-59$.

Noor Hasimah Hasan \& Effandi Zakaria. (2017). Kesediaan Guru Matematik dalam Melaksanakan Pengajaran dan Pembelajaran KBAT. National Pre-University Seminar 2017, 14-23.

Nor Hasmaliza Hasan, \& Zamri Mahamod. (2016). Persepsi Guru Bahasa Melayu Sekolah Menengah Terhadap Kemahiran Berfikir Aras Tinggi. Jurnal Pendidikan Bahasa Melayu, 6(2), 78-90.

Nurzarina Amran, \& Roslinda Rosli. (2015). Kefahaman Guru Tentang Kemhiran Abad ke-21. Prosiding Persidangan Antarabangsa Sains Sosial dan Kemanusiaan, 21, 1-5.

Raiyn, J., \& Tilchin, O. (2015). Higher-Order Thinking Development through Adaptive Problembased Learning. Journal of Education and Training Studies, 3(4), 93-100.

Rajendran, Nagappan. (1998). Teaching Higher Order Thinking Skills in Language Classroom: The Needs for Transformation of Teacher Practice. (Tesis Doktor Falsafah) Michigan State University.

Rohani Arbaa, Hazri Jamil, \& Mohammad Zohir Ahmad. (2017). Model Bersepadu Penerapan Kemahiran Abad ke-21 dalam Pengajaran dan Pembelajaran. Jurnal Pendidikan Malaysia, 42(1), $1-11$.

Rufaizal Che mamat, \& Azuin Ramli. (2017). Kemahiran Belajar Dan Inovasi Dalam Pembelajaran Abad ke-21 Melalui Khemah Kerja Geoteknik. Advance Journal of Technical and Vocational Education, 1(1), 384-389.

Salina Md. Yunas, \& Zamri Mahamod. (2017). Tahap Kesediaan, Sikap dan Amalan Guru Bahasa Melayu Sekolah Rendah Terhadap Penggunaan Peta Pemikiran I-Think. Seminar Serantau 2017, 767-774.

Shanti A/P Gobalakrisnan \& Abdul Said Ambotang. (2019). Pengaruh Tahap Akauntabiliti Guru, Peranan Pentadbir dan Efikasi Kendiri Guru Terhadap Pelaksanaan Pengajaran Abad ke-21 Sekolah Rendah. Malaysian Journal of Social Sciences and Humanities, 4(6), 170-180.

Uminur Atikah \& Effandi Zakaria. (2017). Persepsi Guru Matematik Terhadap Kemahiran Berfikir Aras Tinggi (KBAT) Semasa Pengajaran dan Pembelajaran di Dalam Bilik Darjah. Seminar Pendidikan Transdisiplin (STEd 2017), Fakulti Pendidikan, Universiti Kebangsaan Malaysia, 699-707.

Wan Nor Shairah Sharuji \& Norazah Mohd Nordin. (2017). Kesediaan Guru dalamPelaksanaan Kemahiran Berfikir Aras Tinggi (KBAT). Simposium Pendidikan diPeribadikan: Perspektif Risalah An-Nur, 140-146. 